\title{
NOUVELle
}

\section{La niche neurogénique adulte entre dans la troisième dimension}

Nathalie Spassky, Isabelle Caillé

\author{
N. Spassky: Inserm U711 UPMC, Bâtiment Pharmacie, \\ $5^{\mathrm{e}}$ étage, Hôpital Pitié Salpêtrière \\ 47 boulevard de l'Hôpital, 75013 Paris, France. \\ nathalie.spassky@upmc.fr \\ I. Caillé : Équipe Avenir/Inserm, UMR CNRS 7102, \\ Bâtiment $B, 6^{e}$ étage Boîte 12 , UPMC, \\ 9, quai Saint-Bernard, 75005 Paris, France. \\ isabelle.caille@snv.jussieu.fr
}

> La zone sous ventriculaire (ZSV) des ventricules latéraux du cerveau adulte est, avec la zone subgranulaire du gyrus dentelé de l'hippocampe, une région riche en cellules souches neurales (CSN). Comme dans d'autres organes, ces cellules résident dans un microenvironnement spécialisé (une «niche») susceptible de réguler leur comportement $[1,6]$. L'utilisation future des cellules souches à des fins thérapeutiques implique de mieux comprendre les mécanismes impliqués dans ces régulations. Trois articles publiés dans Cell Stem Cell appliquent des techniques d'imagerie à des préparations entières de zone sous ventriculaire afin de révéler l'architecture tridimensionnelle des interactions entre les différents composants de la niche. Ces études complémentaires fondamentales révèlent une nouvelle vision de la niche neurogénique qui contribuera par la suite à mieux élucider les mécanismes de la régulation des cellules souches neurales in vivo.

\section{Cellules souches neurales et} vaisseaux : une relation intime

Les articles de Tavazoie et al. [2] et de Shen et al. [3] se focalisent sur les interactions entre les cellules de la ZSV et les vaisseaux sanguins. Les cellules vasculaires sont en effet considérées comme des acteurs importants dans d'autres niches de cellules souches. Les auteurs décrivent le réseau vasculaire de la ZSV comme un maillage enchevêtré et superficiel le long de toute la surface du ventricule et localisé juste en dessous de la couche de cellules épendymaires (Figure 1). Les cellules souches et les progéniteurs en phase de prolifération sont situés à proximité immédiate des vaisseaux. Tavazoie et ses collègues décrivent en détail les contacts spécialisés entre ces cellules et les vaisseaux et révèlent en particulier qu'elles établissent des contacts directs avec les vaisseaux, dénués des intermédiaires cellulaires qui constituent habituellement la barrière hémato-méningée (absence de jonctions serrées, ou d'appositions astrocytaires exprimant l'aquaporine 4, ou de couverture péricytaire). Or, les cellules endothéliales sécrètent des facteurs connus pour réguler la biologie des CSN in vitro [4]. Ces nouveaux résultats révèlent donc maintenant comment les CSN pourraient accéder à ces facteurs in vivo. Ces contacts particuliers pourraient favoriser le passage de signaux comme les facteurs de croissance, les hormones, les nutriments ou l'oxygène du sang vers les cellules souches. Ils pourraient également rendre ces cellules plus sensibles à des agents pharmacologiques à visée thérapeutique. Shen et al. [3] s'intéressent aux interactions qu'entretiennent les cellules prolifératives avec la matrice extracellulaire entourant les vaisseaux. Celle-ci est riche en laminine, protéine dont un récepteur (l'intégrine de type $\alpha 6 \beta 1$ ) est exprimé par les cellules de la ZSV. Le blocage de l'interaction de ce récepteur avec la laminine inhibe l'adhérence des cellules de la ZSV aux vaisseaux et augmente leur prolifération. Cela indique que l'interaction avec les vaisseaux est un important régulateur de la neurogenèse dans la ZSV.

\section{L'organisation en rosace de la niche des cellules souches neurales Mirzadeh et al. [5] se focalisent quant à eux sur l'architecture cellulaire de la zone germinative adulte. Grâce à des marqua-}

ges simultanés des bordures cellulaires ( $\beta$-caténine) et des corps basaux des cils ( $\gamma$-tubuline), les auteurs décrivent une organisation unique qu'ils baptisent «pinwheel architecture » que, par défaut, nous traduirons ici par «architecture en rosace». Ils découvrent en effet que les prolongements apicaux émis par les CSN forment des îlots encerclés par des cellules épendymaires. En plus des CSN de type astroglial qui émettent un seul cil primaire dans la lumière ventriculaire [7], et des cellules épendymaires multiciliées, un nouveau type de cellules épendymaires est décrit comme n'émettant que 2 longs cils susceptibles de véhiculer des signaux régulateurs en provenance du liquide céphalo-rachidien (Figure 1). Les prolongements apicaux des CSN sont courts en comparaison des longs prolongements basaux que ces cellules émettent et qui contactent les vaisseaux sanguins, comme cela est décrit également par les deux autres équipes. Des manipulations génétiques, marquant spécifiquement les cellules qui entrent en contact avec le ventricule et leur descendance, montrent que ces cellules sont neurogéniques in vivo et donc capables de produire des neurones du bulbe olfactif [6].

Cette organisation en rosace pourrait donc être fondamentale pour la régulation des cellules souches. En effet, leurs prolongements possèdent des jonctions adhérentes et communiquent entre eux et avec les cellules épendymaires voisines, ce qui pourrait permettre le passage de signaux entre ces cellules. Cette organisation amène enfin les auteurs à dresser un intéressant parallèle entre neurogenèse adulte et embryonnaire. Chez l'embryon, 


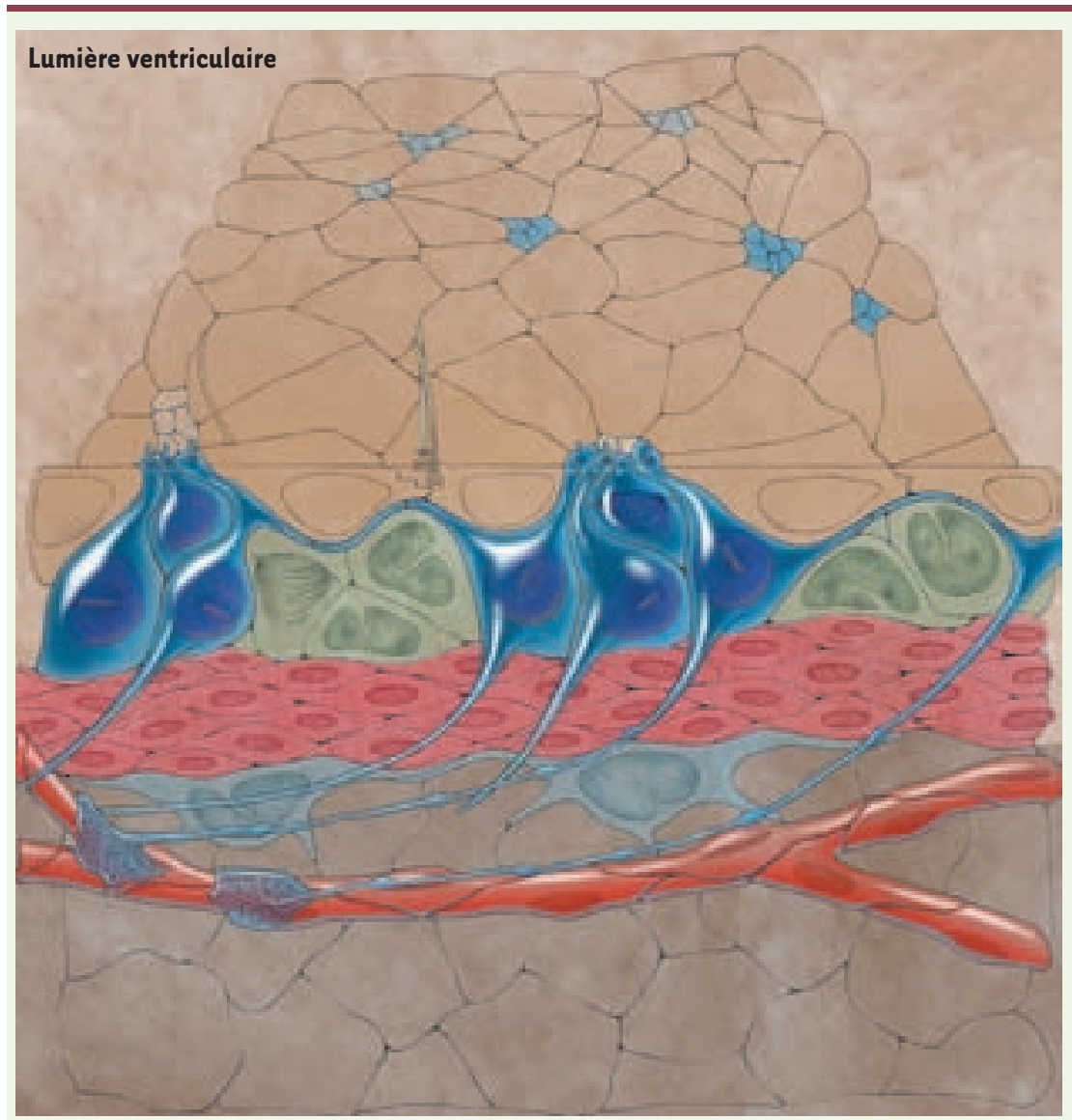

il existe deux zones germinatives distinctes et adjacentes, la zone ventriculaire (ZV), directement apposée au ventricule et composée d'une population homogène de cellules souches, et la ZSV, composée de progéniteurs intermédiaires. Chez l'adulte, une ZV est maintenue, mais devient hétérogène puisque composée des prolongements des CSN mais également des cellules épendymaires. La ZSV persiste également, et elle est composée des progéniteurs et des neuroblastes. La distinction est
Figure 1. Représentation schématique de l'architecture tri-dimensionnelle de la niche neurogénique du cerveau adulte de souris. Les prolongements apicaux émis par les CSN (bleu) sont regroupés en ilots encerclés par des cellules épendymaires (marron) et forment une architecture «en rosace» à la surface ventriculaire. Les prolongements basaux des CSN entourent les progéniteurs (vert) et les neuroblastes en migration (rouge) et contactent les vaisseaux sanguins (orange) (nos remerciements à Kenneth Xavier Probst).

tions. Ces nouvelles perspectives seront probablement lourdes de conséquences sur notre compréhension des régulations fonctionnelles des cellules souches du cerveau adulte et leur potentielle utilisation à des fins thérapeutiques. $\diamond$

Pinwheel architecture of neural stem cell niche, the third dimension

\section{RÉFÉRENCES}

1. Alvarez-Buylla A, Lim DA. For the long run: maintaining germinal niches in the adult brain, Neuron 2004 ; 41 : 683-6.

2. Tavazoie M, Van der Veken L, Silva-Vargas V, et al. A specialized vascular niche for adult neural stem cells. Cell Stem Cell 2008 ; 3 : 279-88.

3. Mirzadeh Z, Merkle F, Soriano-Navarro M, et al. Neural stem cells confer unique pinwheel architecure to the ventricular surface in neurogenic régions of the adult brain. Cell Stem Cell 2008 ; 3 : 265-78.

4. Shen $Q$, Wang $Y$, Kokovay $\varepsilon$, et al. Adult SVZ stem cells lie in a vascular niche: a quantitative analysis of niche cell-cell interactions. Cell Stem Cell 2008; 3: 289-300.

5. Shen $Q$, Goderie SK, Jin L, et al. Endothelial cells stimulate self-renewal and expand neurogenesis of neural stem cells. Science 2004 ; 304 : 1338-40.

6. De Chevigny $A$, Lledo PM. La neurogenèse bulbaire et son impact neurologique. Med Sci (Paris) 2006; 22: 607-13.

7. Spassky N, Aguilar A. Cil primaire et développement cérébral. Med Sci (Paris) 2008 ; $24: 790-1$.

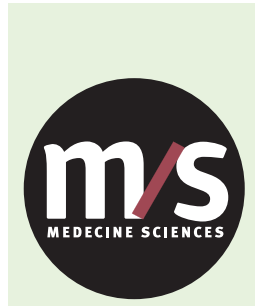

Tarifs d'abonnement M/S - 2009

$>$ Grâce à $m / s$, vous vivez en direct les progrès des sciences biologiques et médicales

Abonnez-vous

à Médecine/Sciences

\section{Bulletin d'abonnement page 30 dans ce numéro de $\mathrm{m} / \mathrm{s}$}
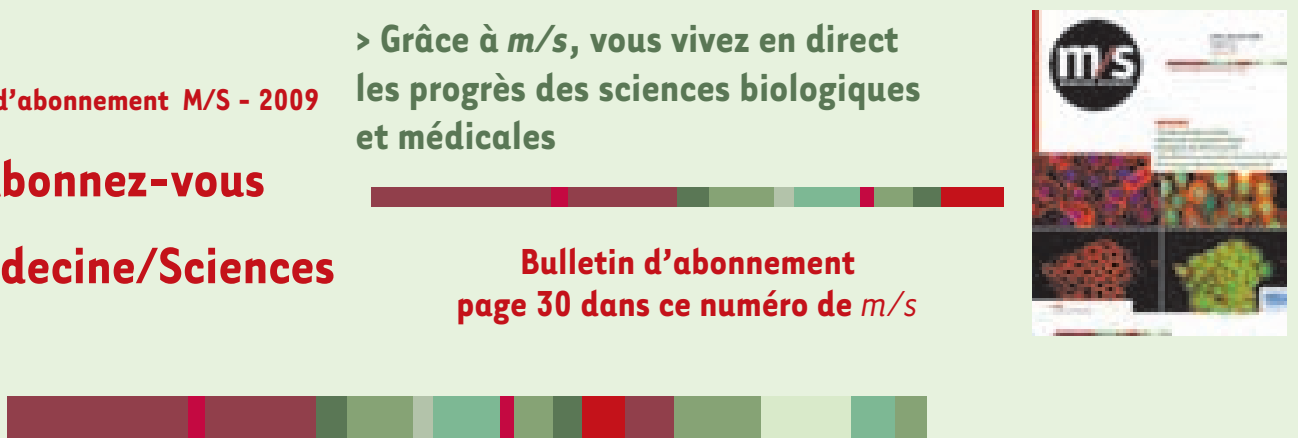